\title{
Risk Factors in the Transmission of Tuberculosis in Nairobi: A Descriptive Epidemiological Study
}

\author{
Perpetual Wangui Ndungu ${ }^{1 *}$, Gunturu Revathi ${ }^{2}$, Samuel Kariuki ${ }^{3}$, Zipporah Ng'ang'a $^{1}$ \\ ${ }^{1}$ Institute of Tropical Medicine and Infectious Diseases (ITROMID), Jomo Kenyatta University of \\ Agriculture and Technology (JKUAT), Nairobi, Kenya \\ ${ }^{2}$ Department of Pathology, Aga Khan University Hospital (AKUH), Nairobi, Kenya \\ ${ }^{3}$ Centre for Microbiology Research, Kenya Medical Research Institute (KEMRI), Nairobi, Kenya \\ Email: *perpetualndungu@yahoo.com, gunturu.revathi@aku.edu, samkariuki2@gmail.com, zipnganga@gmail.com
}

Received March 21, 2013; revised April 20, 2013; accepted May 20, 2013

Copyright (C) 2013 Perpetual Wangui Ndungu et al. This is an open access article distributed under the Creative Commons Attribution License, which permits unrestricted use, distribution, and reproduction in any medium, provided the original work is properly cited.

\begin{abstract}
Background: Tuberculosis is an infectious disease with an estimated 1.45 million deaths every year. Many patients get infected as a result of ignorance of the risk factors that contribute to disease transmission. Methodology: A descriptive epidemiological study was conducted on 258 patients presenting with pulmonary tuberculosis. Patients' sputa were collected for laboratory analysis and patients were required to respond to a structured questionnaire on risk factors for transmission. Data among stratified groups were compared using bivariate analysis. Statistical significance was considered at $p<0.05$. Results: There were significantly more males than females associated with pulmonary tuberculosis infection $\left(\chi^{2}=0.963 ; \mathrm{df}=1 ; \mathrm{p}<0.05\right)$. Monthly income was significant in disease transmission with $222(86.0 \%)$ of the patients earning less than $100 \$$ and $90(34.9 \%)$ earning less than $50 \$$ per month $(\mathrm{p}<0.05,95 \% \mathrm{CI})$. One hundred and seventy three patients $(67.1 \%)$ were unemployed or running small businesses. Only $85(32.9 \%)$ were in formal employment. Results showed $166(64.3 \%)$ patients were living in single rooms with $110(42.6 \%)$ living with more than two people with a maximum of 10 people in a single room. Only $73(28.3 \%)$ were living alone in a single room and only 7 families $(2.7 \%)$ were living in houses with five or more rooms. Alcohol consumers and smokers were 102 $(39.5 \%)$ and $93(36 \%)$ respectively. Half of the patients (137 (53.3\%)) had not completed secondary education with only $16(6.2 \%)$ having completed tertiary education. Recurrent cases were $54(21 \%)$ while those exposed to the disease either at home or working place were $75(29.2 \%)$. Out of 171 patients who agreed to test for HIV, $46(26.9 \%)$ were positive. Marital status had no effect on incidence of disease. Conclusion: Emphasis should be given to creating awareness of the risk factors associated with transmission of tuberculosis in order to reduce the rate of infection.
\end{abstract}

Keywords: Tuberculosis; Risk Factors; Transmission

\section{Introduction}

TB is a communicable disease caused by Mycobacterium tuberculosis (MTB). Although it affects any part of the body, only active pulmonary type of the disease can be transmitted from one person to the other through droplets carrying the TB bacillus. This occurs when a person coughs, sneezes or laughs. The inhaled bacilli eventually reach the lungs and spreads to other parts of the body. A competent immune system will limit the multiplication of the tubercle bacilli although some bacilli may remain dormant but viable causing a condition called latent pulmonary tuberculosis infection (LTBI) [1]. Pulmonary

"Corresponding author. tuberculosis (PTB) according to WHO is a disease of poverty affecting mostly young adults in their productive years [2]. It causes a great deal of ill health and an enormous economic burden in the populations of most lowincome countries. Kenya is one of the high burden TB countries ranking fifteenth among the 22 high burden countries in the world and $5^{\text {th }}$ in Africa. The Kenya National Division of leprosy, TB and lung disease (DLTLD) began to implement WHO direct observation therapy short course (DOTS) in 1993. The DOTS treatment success rate also met WHO's target of $85 \%$ in 2007 [3]. Inspite of all the effort, WHO Global TB report 2009 [4] estimated Kenya had approximately 132,000 new TB cases and an estimated 74,000 people died in that year. 
The country had an incidence rate of 142 new smear positive cases per 100,000 people in 2009. Many risk factors have been associated with the spread of the disease the highest among them being HIV infection which greatly contributes to the continuing threat of TB particularly in Africa and South East Asia [5]. Other factors include low income, substance abuse, coming from TB endemic regions, old age and living in congested facilities $[1,6]$. Few studies in Kenya have focused on the risk factors that could be associated with tuberculosis infection in Kenya. The aim of this study therefore, was to investigate risk factors in pulmonary tuberculosis patients attending various clinics in Nairobi.

\section{Method}

\subsection{Design}

Patients aged 18 years and above were interviewed in a descriptive epidemiological study. Personal data was classified by age, gender, marital status, and level of education, occupation, average income, type and size of house, number of people living in the house. Clinical data was classified by TB history and exposure, other critical illnesses such as HIV status. Personal habits critical to infection were also classified as smoking history, number of cigarettes smoked per day, alcohol consumption and diet.

\subsection{Inclusion and Exclusion Criteria}

Inclusion criteria: All adult patients 18 years and above presenting with pulmonary tuberculosis and who agreed to participate in the program.

Exclusion criteria: All patients below 18 years and adults who refused to participate in the program.

\subsection{Data Collection Tool}

A structured questionnaire was designed based on previous similar studies. It focused on basic demographic data (age, sex, marital status), social economic status (education level, average monthly income, place of residence, type of residence, size of house, assets owned) and personal habits relevant to TB infection (smoking, alcohol consumption and diet). The interview consisted of yes or no and multiple choice questions in which the respondents had to choose only one of the proposed answers. The questionnaire was pilot tested over a two weeks period and modified accordingly. The interviews lasted for 10 - 15 minutes and were conducted in English and Kiswahili (national language in Kenya). The results were retested after completion to verify the answers. As in most analysis on poverty issues in the Kenya family, income was considered the principle social-economic indicator in this study. The non-economic poverty indicators used were residence, education level, occupation.

\subsection{Data Analysis}

Risk factors affecting TB transmission were stratified by sex, age, education (primary, secondary, tertiary), average monthly income $(<50,50-100,100-200,>200 \$)$, employment (employed formal, unemployed, self employed), number of rooms in a house $(1,2-4,>5)$, type of house(mud, iron sheets, timber, stone), number of cigarettes per day $(<10,10-20,20-30,>30)$.

Data among stratified groups were compared in bivariate analysis using $\mathrm{z}$-test and $\chi^{2}$. Multivariate analysis with standard logistic regression described those variables independently related to risk factors associated with TB transmission. Through a 95\% confidence interval (95\% CI) statistical significance was considered at $\mathrm{p}<$ 0.05. Analysis was performed using SPSS 17 (SPSS Inc, Chicago, IL).

Ethical considerations: The study was approved by the National ethical review committee (ERC) at the Kenya Medical Research Institute (KEMRI). Written and informed consents were obtained from the patients.

\section{Results}

Several demographic factors were analyzed including income, gender and age all of which were found to be significant in transmission of PTB ( $p<0.05,95 \%$ CI) (Table 1).

Income emerged as a major significant factor in the spread of PTB ( $p<0.05,95 \% \mathrm{CI})$. Income determines many other factors assessed such as housing, crowding, and alcohol consumption. Among the patients sampled $85.3 \%$ were earning less than $100 \$, 30(11.6 \%)$ were earning $100-200 \$$ and only $6(2.3 \%)$ were earning more than 200\$ per month (Figure 1).

Patients earning less than $100 \$$ had 8.667 times more chances of infection while those earning $100-200 \$$ per month had 3 times more chances of infection and those with an income of more than $200 \$$ had fifty/fifty chance of infection. Re-infection was also found to have been more common in patients with an income between 50 and 200\$. Patients who consumed alcohol were 102 $(39.5 \%)$ and among these $59 \%$ had an income of less than $100 \$$ compared with $41 \%$ of those with an income of more than $200 \$$ per month. Only $16(6.2 \%)$ of the patients had a tertiary education with $5(1.9 \%)$ being were illiterate (Figure 2).

One hundred and two (39.5\%) patients were consuming alcohol while 93 (36\%) were smokers. Employment was another important factor with $173(67.1 \%)$ of the patients being unemployed or self employed in small businesses compared to $32.9 \%$ who were in formal employment. 
Table 1. Demographic characteristics of patients in a descriptive epidemiology study of pulmonary tuberculosis infection $(n=258)$.

\begin{tabular}{|c|c|c|}
\hline Variables & Frequency $(\%)$ & p-value \\
\hline \multicolumn{3}{|l|}{ Gender } \\
\hline Male & $154(59.7)$ & 0.0481 \\
\hline Female & $104(40.3)$ & \\
\hline \multicolumn{3}{|l|}{ Age (yrs) } \\
\hline $18-26$ & $87(33.7)$ & 0.0455 \\
\hline $26-34$ & $85(32.9)$ & \\
\hline $35-40$ & $28(11.2)$ & \\
\hline Above 40 & $58(22.4)$ & \\
\hline \multicolumn{3}{|l|}{ Education } \\
\hline Primary & $120(46.5)$ & 0.846 \\
\hline Secondary & $122(47.2)$ & \\
\hline College & $16(6.2)$ & \\
\hline \multicolumn{3}{|l|}{ Occupation } \\
\hline Unemployed & $92(35.7)$ & \\
\hline Self employed & $81(31.4)$ & \\
\hline Formal employment & $85(32.9)$ & \\
\hline \multicolumn{3}{|l|}{ Income (US\$) } \\
\hline$<50$ & $90(34.9)$ & 0.0465 \\
\hline $50-100$ & $132(51.2)$ & \\
\hline $100-200$ & $30(11.6)$ & \\
\hline Above 200 & $6(2.3)$ & \\
\hline \multicolumn{3}{|c|}{ Housing (No. of rooms in house) } \\
\hline Single & $166(64.3)$ & 0.0653 \\
\hline $2-4$ & $85(32.9)$ & \\
\hline$>5$ & $7(2.7)$ & \\
\hline \multicolumn{3}{|l|}{ Smoking } \\
\hline Smokers & $93(36.0)$ & 0.0810 \\
\hline Non-smokers & $165(63.6)$ & \\
\hline \multicolumn{3}{|l|}{ Alcohol consumption } \\
\hline Alcohol consumers & $102(39.5)$ & 0.0951 \\
\hline Non-consumers & $156(60.5)$ & \\
\hline \multicolumn{3}{|l|}{ HIV status $(n=171)$} \\
\hline $\mathrm{HIV}+$ & $46(26.9)$ & \\
\hline HIV- & $125(73.1)$ & \\
\hline
\end{tabular}
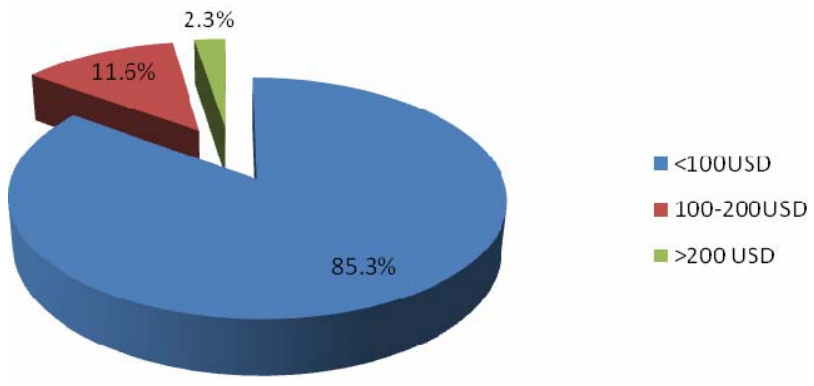

Figure 1. Income of patients per month in USD.
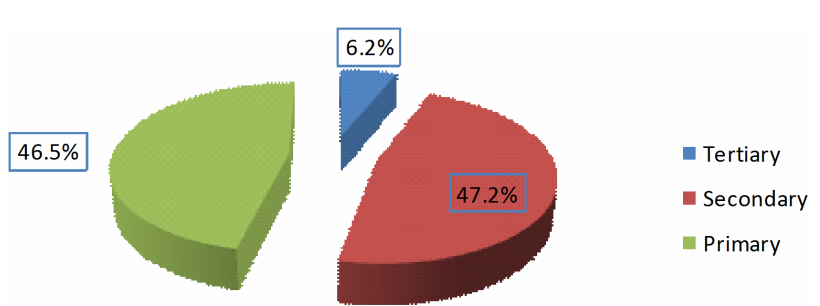

Figure 2. Education level of patients.
Housing conditions were found to have had an effect with TB infection with $166(64.3 \%)$ patients living in single rooms and only $7(2.7 \%)$ patients were living in houses that had more than 5 rooms (Figure 3).

Among those living in single rooms 68 were living with more than two people with some households having as many as 10 people; only $45(17.4 \%)$ were living alone in a single room. Majority of the patients $200(77.5 \%)$ were below the age of 40 years and only 58 (22.4\%) were above the age of 40 years (Figure 4).

There was also a significantly large number of males $154(59.9 \%)$ compared to the females $103(40.1 \%)$ in this study $\left(\chi^{2}=0.963 ; \mathrm{df}=1 ; \mathrm{p}<0.05\right)$ (Figure 5).

Marital status, diet, type of house and material used to construct the house did not have any effect in the rate of infection.

\section{Discussion}

Majority of the patients in this study were male (59.7\%). Nava-Aguilera in a systematic review and meta-analysis of TB infection from various articles published between 1994-2005 showed that being male was one of the risk factors for TB infection [7]. In France, male sex was highly associated with TB infection [8] while in Russia

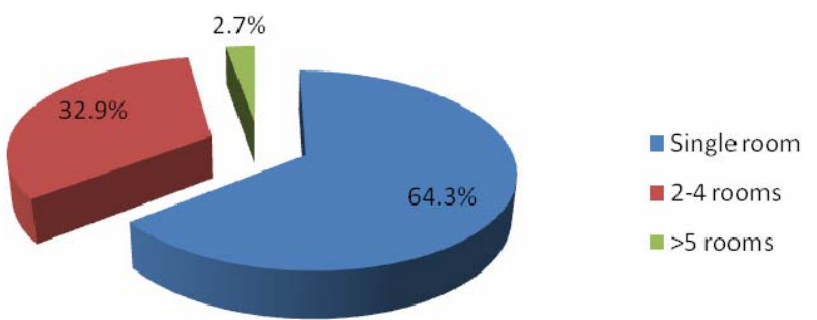

Figure 3. Housing conditions of patients.

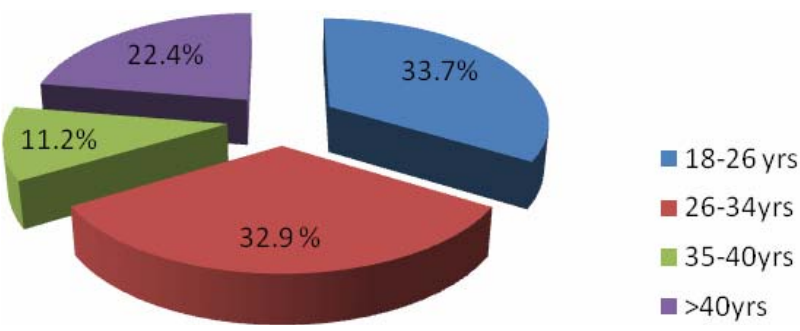

Figure 4. Age distribution of patients.

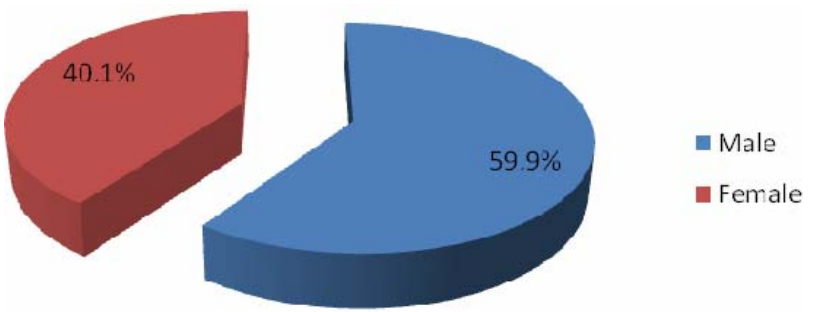

Figure 5. Gender of patients. 
$72 \%$ of the patients were male [9]. WHO report on TB incidences and gender show that the rates are higher in males at all ages except in childhood and notes that the sex differential prevalence begin to appear 10 and 16 years of age; reasons for higher male prevalence and incidences are poorly understood and need further investigation [10].

In this study, majority of the patients were low income groups with $86.1 \%$ earning less than $100 \$$ per month. This is similar to other studies which cited low income groups as being most likely to be infected with TB $[1,6]$. In England and Wales, poverty was a strong risk factor to TB mortality [11]. A study by Dye et al., (2009) from 134 countries revealed that incidences of tuberculosis were falling more quickly in countries with high income than those with low income [12]. A study in the United States found that poverty was also a risk factor in TB infection [13].

From the data smoking and alcohol consumption were associated with TB infection with $36 \%$ of the patients being smokers and $39.5 \%$ being alcohol consumers. In another study in Kenya, patients attributed TB to causes such as smoking and alcohol consumption [14]. In the Philippines TB was also attributed to drinking and smoking and this caused the patients to delay in seeking treatment [15]. In Botswana TB symptoms were often associated with drinking and smoking [16]. A systematic review of association between alcohol use and tuberculosis found those who consumed more alcohol per day and/or have an alcohol disorder have an elevated risk of active tuberculosis [17]. A study in Russia found that $62 \%$ of the patients were alcohol abusers and that alcohol abuse/ dependence was associated with an eight fold increase in drug resistance and relapse [9]. Another study in the Greater Vancouver regional district in Canada showed that smear positive patients had a history of alcohol abuse [18]. In India transmission of TB in children was found to be influenced by among other factors exposure to environmental tobacco smoke [19] while in North-West England patients who smoked were 2.3 times more likely to be infected with TB than the controls who did not smoke [20].

Crowding was also found to be associated with incidences of TB with $64.3 \%$ of families living in single rooms some with as many as 10 people. This is because living quarters with less space facilitate the spread of infection. This is similar to studies in India where $73.3 \%$ of patients lived in overcrowded residences [21]. In Pakistan, overcrowding was found to affect $75 \%$ of the study population [22] while in England and Wales there was a strong association between TB mortality and overcrowding at the household level [14]. In Gambia TB cases increased with crowding [23] and in the United States crowding was one of the factors contributing to TB in- fection [13]. In Bangkok Thailand crowding was one of the risk factors for TB infection in household contacts of TB patients [24].

Age was an important factor in this study with $77.5 \%$ of the patients being under 40 years and only $22.4 \%$ above the age of 40 years. In an editorial report, TB incidences were associated with young adult age which creates a main obstacle towards a sound economic and social development of countries where TB is endemic [25]. In South Africa tuberculin skin test increased from $28 \%$ in 5 - 10 years old to $88 \%$ in 31 - 35 year olds [26] while in The Gambia $90 \%$ of the patients were below the age of 49 years [27]. In Pakistan, only $24 \%$ of the prisoners with pulmonary TB were above the age of 42 years [28].

In this study $66.1 \%$ patients were unemployed or working in small business ventures. In Gambia, only 3 of 100 patients were employed while majority were either unemployed or working in unskilled labor [23]. In the United States unemployment was one of the factors responsible for TB infection [13] and in Pakistan 23\% of patients were unemployed while $75 \%$ worked on a daily wage basis [28].

Only $6.2 \%$ of the patients in this study had tertiary education while $46.5 \%$ had only primary education. In the United States low education was one of the risk factors for TB infection [13] and in Pakistan more than half of the patient population had no formal education $(\mathrm{OR}=$ $2.2,95 \%$ CI: $1.4,3.4)$ [28].

\section{Conclusions}

Consistent with other studies elsewhere this study showed that patients prone to TB infection earn less than $100 \$$ and are more likely to be unemployed or self employed in small businesses, live in a single room, are more often male and they smoke or consume alcohol. There is a need to create awareness in the population on the risk factors that lead to TB transmission in order to reduce the incidence of the disease. There is also need to carry out similar studies on risk factors in other localities in the country in order to have a comparative analysis.

List of abbreviations: TB-Tuberculosis, PTB-Pulmonary tuberculosis, WHO-World Health Organization, MTB-Mycobacteria tuberculosis, LTBI-Latent TB infection, DLTLD-Division of leprosy, TB and lung disease, HIV-Human immunodeficiency virus, DOTSDirect observation therapy short course, \$-United States Dollar, ERC—Ethical review committee, KEMRI—Kenya medical research institute.

Competing interests: The authors declare that they have no competing interests.

Authors' contribution: PWN corrected the data, undertook the statistical analysis and drafted the manuscript, 
GR initiated the study and together with SM and ZN made major contributions in the study design. All authors contributed to the writing of the manuscript and approved the submitted version.

\section{Acknowledgements}

The authors wish to acknowledge the grant support provided by the African Doctoral Dissertation Research Fellowship (ADDRF) and a fellowship offered by the African Population and Health Research Centre (APHRC) in partnership with the International Development Research Centre (IDRC) and the Ford foundation. This study could not have been possible without the support of the pathology department at the Aga Khan University Hospital in allowing utilization of their laboratory facility to carry out the study. Special thanks to Henry Gatu and Caroline Kasera for their unconditional support during this study and to the head of the microbiology section, Mr. Nelson Kuria, and all the microbiology staff. The authors acknowledge DLTLD for providing external QS for the laboratory procedures.

\section{REFERENCES}

[1] CDC, "Core Curriculum on Tuberculosis: What Clinicians Should Know," 5th Edition, US Department of Health and Human Services, Atlanta, 2000.

http://www.cdc.gov/tb/education/corecurr/default.htm

[2] WHO, "Gl Tuberculosis Control Report," 2010. http://www.who.int/tb/publication/global_report/2010/en/ index.html

[3] Ministry of Health, "National Leprosy and Tuberculosis Program (NLTP). Annual Report,” 2007.

http://www.nltp.co.ke/docs/Annual_Report_2007.pdf

[4] WHO, "Global Tuberculosis Control Report," 2009. http://www.who.int/tb/publications/global_report 2009/pdf/full_report.pdf

[5] WHO, "Global Tuberculosis Control," 2001. http://whqlibdoc.who.int/hq/2001/who_CDS TB 2001.2 87.pdf

[6] J. M. Grange, "The Global Burden of Tuberculosis," In: J. D. Porter and J. M. Grange, Eds., Tuberculosis. An Interdisciplinary Perspective, Imperial College Press, Singapore, 1999 , pp. 3-31. doi:10.1142/9781848160552 0001

[7] E. Nava-Aguilera, N. Anderson, E. Harris, S. Mitchell, C. Hamel, B. Shea, Y. Lopez-Vidal, A. Villegas-Awizon and A. Morales-Perez, "Risk Factors Associated with Recent Transmission of Tuberculosis. Systematic Review and Metaanalysis," International Journal of Tuberculosis and Lung Disease, Vol. 13, No. 1, 2009, pp. 17-26.

[8] M. Gutierrez, V. Vincent, D. Aubert, J. Bitez, O. Gaillot, L. Lebrun, C. Le Pendeven, M. Le Pennec, D. Mathieu, C. Offrendo, B. Pangon and Pierre-Audigier: "Molecular Fingerprinting of Mycobacterium Tuberculosis. Risk Factors for Tuberculosis Transmission in Paris, France and Sur- rounding Area," Journal of Clinical Microbiology, Vol. 36, No. 2, 1998, pp. XGH486-XGH492.

[9] M. F. Fleming, E. Krupitsky, M. Tsoy, E. Zoartau, N. Brazhenko, W. Jakubowiak and M. E. McCaul, "Alcohol and Drug Use Disorders, HIV Status and Drug Resistance in a Sample of Russian Patients," International Journal of Tuberculosis and Lung Disease, Vol. 10, No. 5, 2006, pp. 65-70.

[10] WHO, "Gender and Health. Gender and Tuberculosis," 2002. http://whlibdoc.who.int/gender/2002/a85584.pdf

[11] F. Elender, G. Betham and I. Langford, "Tuberculosis Mortality in England and Wales during 1982-1992. Its Association with Poverty, Ethnicity and AIDS," Social Science and Medicine, Vol. 46, No. 6, 1998, pp. 673-681. doi:10.1016/S0277-9536(97)00178-0

[12] C. Dye, K. Lonnroth, E. Jaramillo, B. G. Williams and M. Raviglione, "Trends in Tuberculosis Incidence and Their Determinants in 134 Countries," Bulletin of World Health Organization, Vol. 87, No. 9, 2009, pp. 683-691. doi:10.2471/BLT.08.058453

[13] M. F. Cantwell, M. T. McKenna, E. McCray and I. M. Onorato, "Tuberculosis and Race/Ethnicity in the United States: Impact of Socioeconomic Status," American Journal of Respiratory and Critical Care Medicine, Vol. 157, No. 4, 1998, pp. 1016-1020. doi:10.1164/ajrccm.157.4.9704036

[14] R. Liefooghe, J. B. liddawa, E. M. Kipruto, C. Vermeire and A. O. Munynck, "From Their Perspective. A Kenyan Community's Perception of Tuberculosis," Tropical Medicine and International Health, Vol. 2, No. 8, 1997, pp. 809-821. doi:10.1046/j.1365-3156.1997.d01-380.x

[15] C. Auer, J. Sarol Jr., M. Tanner and M. Weiss, "Health Seeking and Perceived Causes of Tuberculosis among Patients in Manilla Phillipines," Tropical Medicine and International Health, Vol. 5, No. 9, 2000, pp. 648-656.

[16] T. W. Steen and G. N. Mazonde, "Ngaka ya Setswana Ngaka ya Sekgoa or both? Health Seeking Behavior in Botswana with Pulmonary Tuberculosis," Social Science and Medicine, Vol. 48, No. 2, 1999, pp. 163-172. doi:10.1016/S0277-9536(98)00329-3

[17] K. Lonnroth, B. G. Williams, S. Stadlin, E. Jaramillo and C. Dye, "Alcohol Use as a Risk Factor for TuberculosisA Systematic Review," BMC Public Health, Vol. 8, No. 289, 2008, p. 289. doi:10.1186/1471-2458-8-289

[18] E. Hernandez-Gardano, V. Cook, D. Kunimoto, R. K. Elwood, W. A. Black and J. M. Fitz Gerrald, "Trans-mission of TB from Smear Positive Patients: A Molecular Epidemiology Study," Thorax, Vol. 59, No. 4, 2004, pp. 286-290. doi:10.1136/thx.2003.011759

[19] M. Singh, M. L. Mynak, L. Kumar, J. L. Matthew and S. K. Jindal, "Prevalence and Risk Factors for Transmission of Infection among Children in Household Contact with Adult Having Pulmonary TB," Archives of Disease in Childhood, Vol. 90, No. 6, 2005, pp. 624-628.

doi:10.1136/adc.2003.044255

[20] K. Toque, M. A. Bellis, N. J. Beeching, Q. Syed, T. Remmington and P. D. O. Davies, "A Case-Control Study of Lifestyle Risk Factors Associated with Tuberculosis in Liverpool, North-West England," European Respiratory 
Journal, Vol. 18, No. 6, 2001, pp. 959-964. doi:10.1183/09031936.01.00211701

[21] M. Khurram, H. T. B. Khaar and M. Fahim, "Multi-Drug Resistant Tuberculosis in Rawalpindi, Pakistan," Journal of Infection in Developing Countries, Vol. 6, No. 1, 2012, pp. 29-32.

[22] A. R. Alvi, S. F. Hussain, M. A. Shah, M. Khalida and M. Shamsudin, "Prevalence of Pulmonary TB on the Roof of the World," International Journal of Tuberculosis and Lung Disease, Vol. 2, No. 11, 1998, pp. 909-913.

[23] P. C. Hill, D. Jackson-Sillah, S. A. Donkor, J. Out, R. A. Adegbola, C. Lienhardt, "Risk Factors for Pulmonary Tuberculosis: A Clinical Based Case Study in the Gambia," BMC Public Health, Vol. 6, No. 289, 2006, p. 156. doi:10.1186/1471-2458-6-156

[24] S. Tornee, J. Kaewkungwal, W. Fungladda, U. Silachmroon, P. Akarasewi and P. Sunakorn: "Risk Factors for Tuberculosis Infection among Household Contacts in Bangkok Thailand," The Southeast Asian Journal of Tropical Medicine and Public Health, Vol. 35, No. 2, 2004, pp. 375-383.
[25] F. Giovanni, "Tuberculosis: Novel Approaches to an Old Disease," Journal of Infection in Developing Countries, Vol. 6, No. 1, 2012, pp. 4-5.

[26] R. Wood, H. Liang, H. Wu, K. Middlekoop, T. Oni, M. X. Rangaka, R. J. Wilkinson, L. G. Bekker and S. D. Lawn, "Changing Prevalence of Tuberculosis Infection with Increasing Age in High Burden Townships in South Africa," International Journal of Tuberculosis and Lung Disease, Vol. 14, No. 4, 2010, pp. 406-412.

[27] C. Lienhardt, K. Fielding, J. Sillah, A. Tunkara, S. Donkor, K. Manneh, D. Warndorff, K. P. Mc Adam and S. Bennet, "Risk Factors for Tuberculosis Infection in SubSahara Africa. A Contact Study in the Gambia," American Journal of Respiratory and Critical Care Medicine, Vol. 168, No. 4, 2003, pp. 448-455. doi:10.1164/rccm.200212-1483OC

[28] Akhtar, "Prevalence of and Risk Factors Associated with Mycobacterium Tuberculosis Infection in Prisoners, North West Frontier Province Pakistan," International Journal of Tuberculosis and Lung Disease, Vol. 32, No. 5, 2003, pp. 794-799. 